\title{
Platelet-Derived Growth Factors and Growth- Related Genes in Rat Lung. III. Immunolocalization during Fetal Development
}

\author{
ROBIN N. N. HAN, CAROLYN MAWDSLEY, PATRICIA SOUZA, A. KEITH TANSWELL, \\ AND MARTIN POST \\ Neonatal Division, Department of Paediatrics, Hospital for Sick Children Research Institute, Toronto, Ontario, \\ Canada M5G $1 X 8$
}

\begin{abstract}
To further study the role of platelet-derived growth factor (PDGF) in fetal lung development, the distribution of the PDGF homodimers PDGF-AA and PDGFBB was examined by immunohistochemistry in embryonic and fetal rat lung from $\mathrm{d} \mathbf{1 2}$ to 22 of gestation (term $=22$ d). PDGF-AA and PDGF-BB were localized to airway epithelial cells as early as d 12 of gestation, $2 \mathrm{~d}$ before their appearance in mesenchymal cells. Both PDGF homodimer immunoreactivities increased until the late pseudoglandular stage of lung development, followed by fluctuations in reactivity during the canalicular stage. Only weak immunoreactivity to either PDGF homodimer was evident during the saccular stage of lung development. Immunodetection by Western blotting revealed that PDGF-AA and PDGF-BB homodimer protein concentrations were high during the embryonic and pseudoglandular stage of lung development and decreased with advancing gestation. We conclude that the presence of PDGF in both developing airway epithelial cells and mesenchymal cells, as well as gestation-dependent changes of PDGF homodimers, is compatible with a role for this growth factor during fetal lung development. (Pediatr Res 31: 323-329, 1992)
\end{abstract}

\section{Abbreviations}

PDGF, platelet-derived growth factor

TBS, Tris-buffered saline

NGS, normal goat serum

The mammalian lung develops from an endodermal tube, derived from an invagination of the primitive foregut, entering the splanchnic mesoderm. This embryonic stage is followed by the pseudoglandular stage of sequential tubular bifurcations. In the subsequent canalicular stage, there is vascularization of the developing lung, which is followed by the saccular stage of acinar development (1). Because lung organogenesis involves cell proliferation, migration, and differentiation, the ontogenic sequence of these events in lung morphogenesis needs to be well coordinated. Polypeptide growth factors are believed to play a vital role in a number of these cellular processes, including cell proliferation, migration, differentiation, and regulation of extracellular matrix composition. Epidermal growth factor has been shown to influence growth of airway epithelium $(2,3)$, and insulin-like growth factor has been localized to the respiratory epithelium (4,

Received June 24, 1991; accepted November 21, 1991.

Correspondence: Dr. M. Post, Division of Neonatology, Hospital for Sick Children, 555 University Ave., Toronto, Ontario, M5G 1X8 Canada.

Supported by Grants PG-42 and MT-7867 from the Medical Research Council of Canada.
5). Transforming growth factor- $\beta_{1}$, which may modulate extracellular matrix composition, also appears to play a role in lung branching morphogenesis (6).

PDGF, a known mitogen for cells of mesenchymal origin, consists of two peptide chains, denoted $A$ and $B$, which can be dimerized (7) in various active isoforms (PDGF-AA, -AB, -BB). The three isoforms differ in their functional properties as well as in their secretory behavior (8). Both the A-chain and B-chain precursors contain signal sequences that allow PDGF-AA and PDGF-AB to be rapidly secreted from their producer cell. A 24$\mathrm{kD}$ form of PDGF-BB remains, to a large extent, associated with the producer cell, and relatively small amounts of $30-\mathrm{kD}$ PDGF$\mathrm{BB}$ are secreted $(9,10)$. Binding of the PDGF ligand to highaffinity cell surface receptors elicits a cascade of intracellular changes that lead to DNA synthesis and cell proliferation. PDGF receptors have been found on most mesenchymal connective tissue-forming cells, including fibroblasts, osteoblasts, chrondroblasts, smooth muscle cells, glial cells, and microvascular (capillary) endothelial cells. Although initial studies of the PDGF molecule suggested that it was primarily a mitogen for connective tissue-derived cells, recent findings have shown that it may induce growth of some epithelial cells $(11,13)$. In addition, PDGF receptors have been reported to be present on mammary, skin (11), and olfactory (12) epithelial cells.

In a recent study, we reported gestation-dependent changes in PDGF-A and PDGF-B transcripts during late fetal rat lung development (14). The ontogenic pattern of PDGF gene expression was similar to that of the cell cycle-related genes DNA polymerase $\alpha$ and histone 3 , with a marked increase of expression during the canalicular stage of lung maturation followed by a decrease during the saccular stage. These findings are compatible with a role for PDGF molecules in lung cell proliferation during late stages of rat lung development. Inasmuch as we have previously observed that both microvascular endothelial cells (15) and epithelial cells (16) purified from fetal rat lung will divide in response to PDGF, it was of interest to determine if PDGF was localized to these cell types in vivo and to determine their ontogeny using Western blot immunoanalysis. The cellular localization and content of PDGF molecules in the developing lung has not, to our knowledge, been previously reported.

\section{MATERIALS AND METHODS}

Materials. Rabbit polyclonal antibodies to human PDGF-AA and PDGF-BB were from Genzyme (Boston, MA). Human recombinant PDGF-AA and PDGF-BB were from Upstate Biotechnology (Lake Placid, NY). Rabbit PAP (peroxidase-antiperoxidase) soluble immune complex was from ICN Immuno Biologicals (Costa Mesa, CA). An avidin-biotin complex (Vectastain) kit was from Vector Laboratories (Burlingame, CA). Embedding media (O.C.T. compound) was from Miles (Elkhart, IN). Nitro- 
cellulose membrane was from Schleicher and Schuell (Keene, NH).

Wistar rats were originally obtained from Charles River (St. Constant, Quebec, Canada), and were maintained as a breeding colony within our animal services facilities. Pregnant dams carrying fetuses of known gestational age were killed by exposure to an excess of ether. The uterus was exposed, and the embryos and fetuses were delivered. Whole embryos were studied on $\mathrm{d} 12$ of gestation, and the lungs were removed for study from 13 to $22 \mathrm{~d}$ gestation $($ term $=22 \mathrm{~d}$ )

Immunohistochemistry of $P D G F-A A$ and $P D G F-B B$. Tissues for cryosection were fixed as described by Simmons et al. (17). Sections $(5 \mu \mathrm{m})$ were cut on a cryotome and mounted on $\alpha$ aminopropyltriethoxysilane-coated slides. The avidin-biotin immunoperoxidase method (18) was used to study the immunolocalization of PDGF-AA and PDGF-BB in rat fetal lungs. Embedding medium from the cryosections was dissolved in PBS. Endogenous peroxidases were quenched in $1 \%$ (vol/vol) hydrogen peroxide in methanol for $30 \mathrm{~min}$. Nonspecific binding sites were blocked by using 5\% (vol/vol) NGS and $1 \%$ (wt/vol) BSA in PBS for $30 \mathrm{~min}$. The excess of blocking solution was carefully blotted at the edges of the tissue sections and the sections were incubated overnight at $4^{\circ} \mathrm{C}$ with 1:300 dilutions of rabbit antihuman PDGF-AA or PDGF-BB. Subsequent procedures were conducted at room temperature. The tissue sections were washed three times in PBS, then incubated with a 1:200 dilution of biotinylated secondary goat anti-rabbit IgG for $2 \mathrm{~h}$. After they were washed an additional three times in PBS, the tissue sections were incubated with an avidin-biotin complex for $1 \mathrm{~h}$. Slides were washed again in PBS and developed in $0.075 \%$ (wt/vol) $3,3^{\prime}$-diaminobenzidine in Tris- $\mathrm{HCl}$ buffer, $\mathrm{pH} 7.6$, containing $0.002 \%$ (vol/vol) hydrogen peroxide. Tissue sections were lightly counterstained with Carazzi's hematoxylin, dehydrated in an ascending ethanol series then xylene, and mounted.

Dot-blot immunoanalysis showed the absence of any PDGF reactive molecules in NGS, and deletion of NGS from the blocking solution did not affect the PDGF immunostaining pattern. In control experiments, anti-PDGF IgG was replaced with preimmune or nonimmune rat or rabbit sera, or with blocking solution (5\% NGS and 1\% BSA). No immunostaining was observed under these conditions. Immunoabsorption studies, which were conducted by incubating the primary antibodies with excess human recombinant PDGF-A and PDGF-B homodimers for $2 \mathrm{~h}$, also resulted in an absence of immunostaining.

Western blot immunoanalysis. Embryonic and fetal lungs from d 14 to 22 of gestation were dissected and placed briefly in icecold PBS. They were then homogenized in a Dounce (Vineland, $\mathrm{NJ}$ ) homogenizer with five volumes of lysis buffer containing 10 $\mathrm{mM}$ Tris, $140 \mathrm{mM}$ sodium chloride, $1 \%$ (vol/vol) Triton-X 100, $0.1 \%$ (wt/vol) SDS, and $1 \mathrm{mM}$ phenylmethylsulfonyl fluoride. The homogenates were left on ice for $4 \mathrm{~h}$ before centrifugation at $10000 \times g$ for $10 \mathrm{~min}$. Protein content was estimated according to Bradford (19). Aliquots from lung homogenates of each gestational age, containing $300 \mu \mathrm{g}$ of protein, were diluted with sample buffers and separated by gel electrophoresis as described by Laemmli (20). Unreduced conditions and $10 \%$ (wt/ vol) polyacrylamide gels were used for studies of PDGF-AA and PDGF-BB. Proteins were electrophoretically transferred from the polyacrylamide gels to nitrocellulose membranes (21). Nonspecific binding was blocked by incubation with $5 \%$ NGS and $1 \%$ BSA (PDGF-AA and -BB) in TBS for $1 \mathrm{~h}$ at room temperature while the samples were shaken, followed by an overnight incubation with antibodies diluted 1:200. The membranes were incubated with 1:4000 goat anti-rabbit IgG for $2 \mathrm{~h}$, followed by 1:1000 rabbit PAP soluble complex for $30 \mathrm{~min}$. The membranes were thoroughly washed with cold TBS (three times for $10 \mathrm{~min}$ ) between each incubation step. The peroxidase reaction was developed using $0.03 \%$ (vol/vol) hydrogen peroxide, $0.1 \%$ (wt/vol) diaminobenzidine tetrahydrochloride, $0.075 \%$ (wt/vol) cobalt chloride in TBS, pH 7.8.
RESULTS

Immunoreactivity of $P D G F-A A$ and $P D G F-B B$. The lung bud from whole embryo sections of $12 \mathrm{~d}$ gestation showed positive immunoreactivity to PDGF-BB in the epithelial lining of the primitive airway, but not in the surrounding mesenchyme (Fig. $1 b$ ). Positive immunoreactivity to PDGF-AA was also observed in ependymal and mantle layers of the developing brain vesicles, which develop into neurons and some glial cells in later stages of development (Fig. 1a). This finding is consistent with previous studies that demonstrated PDGF-A and PDGF-B expression in neurons $(22,23)$. The lung at $13 \mathrm{~d}$ gestation showed a distribution of immunoreactivity similar to that seen in the lung bud at $12 \mathrm{~d}$ gestation (Fig. $1 c$ and $d$ ). A few mesenchymal cells with positive immunoreactivity to both PDGF were first noted in the lung at $14-15 \mathrm{~d}$ gestation (Fig. $1 e$ and $f$ ). The number of immunoreactive mesenchymal cells in the lung increased until d 17 of gestation. Strong expression of PDGF (AA and BB) in airway epithelial cells was detected until d 17 of gestation (Figs. $1 e$ and $f$ and $2 c$ and $d$ ). PDGF-AA showed weaker reactivity than PDGF$\mathrm{BB}$ in both epithelial and interstitial cells of fetal lung at $18 \mathrm{~d}$ gestation. The intensity of immunoreactivity to both PDGF, as well as the total number of immunoreactive cells, was reduced in both the airway epithelial cells and interstitial cells of the fetal lung at $19 \mathrm{~d}$ gestation compared with lungs of earlier gestational ages (Fig. $2 e$ and $f$ ). Areas of intense immunoreactivity to both PDGF were again observed in the fetal lung at $20 \mathrm{~d}$ gestation, with a significant increase in the number of immunoreactive epithelial cells lining the large airways (Fig. $3 c$ ) and distal respiratory tubules and the number of immunoreactive interstitial cells (Fig. $3 a, b$, and $d$ ). In addition, positive immunoreactivity to both PDGF was seen in chondrocytes of the tracheal rings and in smooth muscle cells surrounding blood vessels (Fig. $3 a$ and $b$ ) and large airways. Endothelial cells lining large vessels did not express either form of PDGF during fetal lung development (Fig. $2 c$ and $d$ ). Expression of PDGF-AA and PDGF-BB during the saccular stage of lung development ( 21 and $22 \mathrm{~d}$ of gestation) was quite distinct from that observed in the late canalicular stage at $20 \mathrm{~d}$ gestation. Weakly positive immunoreactivity to PDGF$\mathrm{AA}$ and PDGF-BB was observed in smooth muscle cells surrounding the airways and large vessels and in a few macrophages, with no immunoreactivity of epithelial cells in the saccular region (Fig. $3 e$ and $f$ ).

Mesothelial cells of embryonic lung at 12 and $13 \mathrm{~d}$ gestation showed no PDGF immunoreactivity. A few mesothelial cells showing immunoreactivity to both PDGF were seen in the fetal lung at $14 \mathrm{~d}$ gestation, after which there was a progressive increase in immunoreactive cells from 15 (Fig. $1 e$ and $f$ ) to $18 \mathrm{~d}$ gestation. Mesothelial cells lost their immunoreactivity to PDGF from $d$ 19 of gestation onward.

Western blot immunoanalyses. Single protein bands were detected at $32 \mathrm{kD}$ with antibody to PDGF-AA and at $28 \mathrm{kD}$ with antibody to PDGF-BB, consistent with the reported molecular mass for PDGF dimers (7). Both PDGF-AA and PDGF-BB protein levels were high during the pseudoglandular period $(\mathrm{d}$ 14-17) of rat lung development (Figs. 4 and 5). The protein content of PDGF-AA declined from d 18 gestation onward and was barely detectable during the saccular stage (d 21-22) of development (Fig. 4). PDGF-BB expression also declined from d 18 gestation to term (Fig. 5).

\section{DISCUSSION}

The present study localized both PDGF-AA and PDGF-BB in airway epithelial cells as well as in mesenchymal cells of developing rat lung. Immunoreactivity to both dimeric forms of PDGF was detected in airway epithelial cells as early as d 12 of gestation in the embryonic lung, $2 \mathrm{~d}$ before the appearance of immunoreactivity in mesenchymal cells. PDGF-AA and PDGF$\mathrm{BB}$ immunoreactivity was detected in mesenchymal cells from d 14 of gestation onward, whereas immunoreactivity to both 

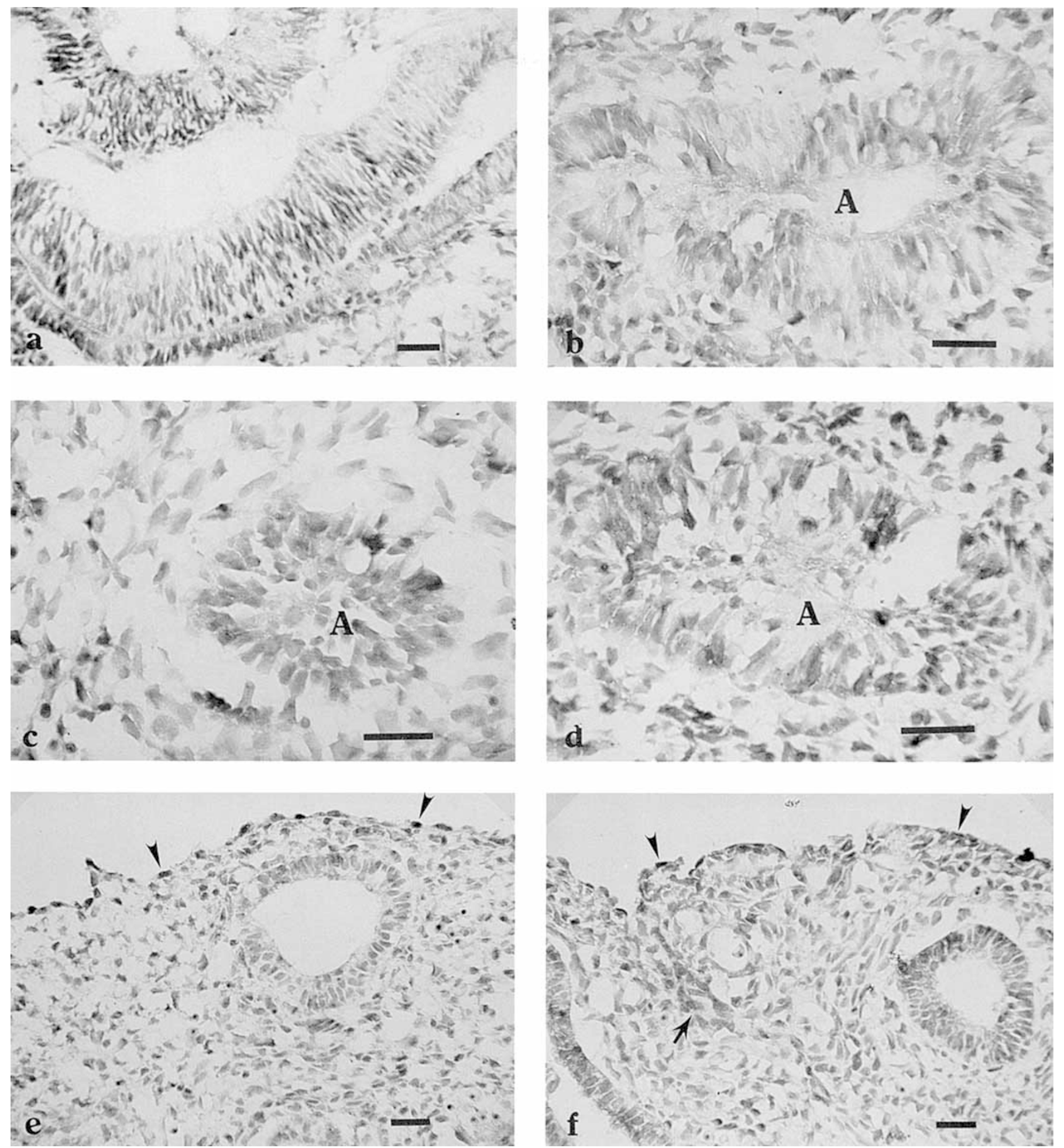

Fig. 1. Immunolocalization of PDGF-AA and PDGF-BB in rat embryonic and early pseudoglandular stage of lung development. PDGF-AA, left panels $(a, c$, and $e$ ) and PDGF-BB, right panels $(b, d$, and $f$ ). Bar equals $100 \mu \mathrm{m}$. $a$, Positive immunoreactivity to PDGF-AA in cells lining the brain vesicle (myelencephalon) in a d 12 gestation embryo. $b$, The airway $(A)$ epithelial lining of the lung bud from a $\mathrm{d} 12$ embryo shows positive immunoreactivity to PDGF-BB. Negative immunoreactivity in the surrounding mesenchyme. $c$, Day 13 embryonic lung shows positive immunoreactivity to PDGF-AA in airway $(A)$ epithelial cells but not in the surrounding mesenchyme. $d$, Positive immunoreactivity to PDGF-BB in airway $(A)$ epithelial cells of $\mathrm{d} 13$ embryonic lung but not in the surrounding mesenchyme. $e$, Fetal lung at $15 \mathrm{~d}$ gestation showing positive immunoreactivity to PDGF-AA in airway epithelial cells, mesenchymal cells, and mesothelial cells (arrowheads). $f$, Positive immunoreactivity to PDGF-BB in airway epithelial cells, mesothelial cells (arrowheads), and interlobar connective tissue (arrow) in a d 15 fetal lung. 

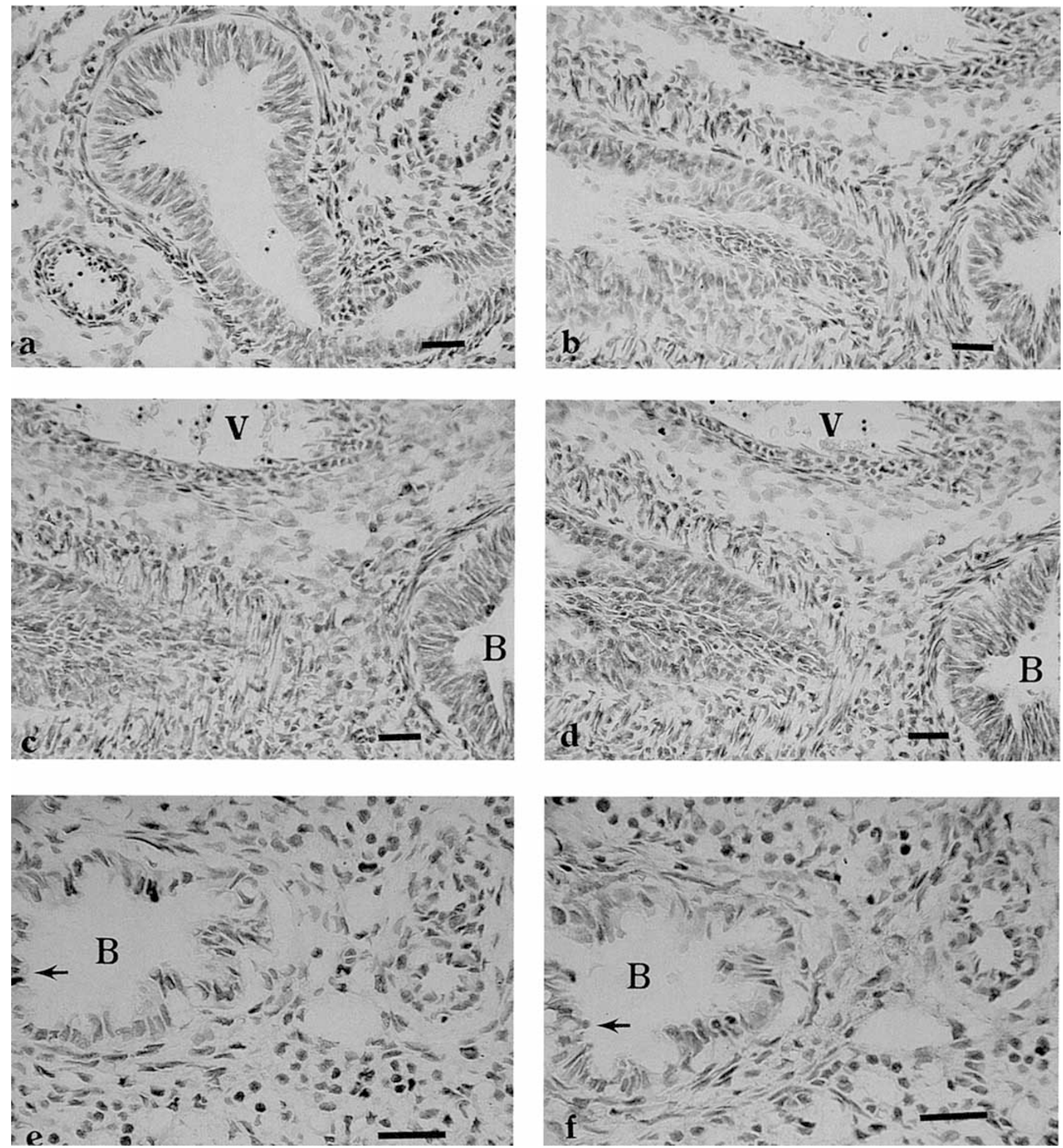

Fig. 2. Immunolocalization of PDGF-AA and PDGF-BB in late pseudoglandular and early canalicular stages of lung development. PDGF-AA, left panels $(a, c$, and $e$ ) and PDGF-BB, right panels $(b, d$, and $f)$. Bar equals $100 \mu \mathrm{m}$. $a$, Negative immunoreactivity to PDGF-AA in fetal lung of 17 $\mathrm{d}$ gestation after immunoabsorption. $b$, Negative immunoreactivity to PDGF-BB in fetal lung of $17 \mathrm{~d}$ gestation after immunoabsorption. $c$, Fetal lung at $17 \mathrm{~d}$ gestation demonstrating positive immunoreactivity to PDGF-AA in bronchial $(B)$ epithelial cells and interstitial cells but not in endothelial cells lining the large vessel $(V) . d$, Fetal lung at $17 \mathrm{~d}$ gestation demonstrating positive immunoreactivity to PDGF-BB in bronchial $(B)$ epithelial cells and interstitial cells but not in endothelial cells lining large vessel $(V)$. $e$, Negative immunoreactivity to PDGF-AA in epithelial cells (arrow) of bronchus $(B)$ and in interstitial cells in d 19 fetal lung. $f$, Fetal lung at $19 \mathrm{~d}$ gestation demonstrating weak immunoreactivity to PDGF$\mathrm{BB}$ in few epithelial cells (arrow) lining the bronchus $(B)$ and few smooth muscle cells surrounding it.

PDGF homodimers was evident in airway epithelial cells from 12 to 17 d gestation. Loss of PDGF-AA reactivity preceded loss of PDGF-BB reactivity in fetal lung of $18 \mathrm{~d}$ gestation, and an additional reduction in intensity of immunoreactivity to both PDGF homodimers and the number of immunoreactive epithe- lial and mesenchymal cells was evident by $19 \mathrm{~d}$ gestation. The number of PDGF-AA and PDGF-BB immunoreactive cells increased markedly at $20 \mathrm{~d}$ gestation, primarily involving the epithelial cells lining the large airways and the distal respiratory tubules. Autoradiographic studies (24) have demonstrated that 

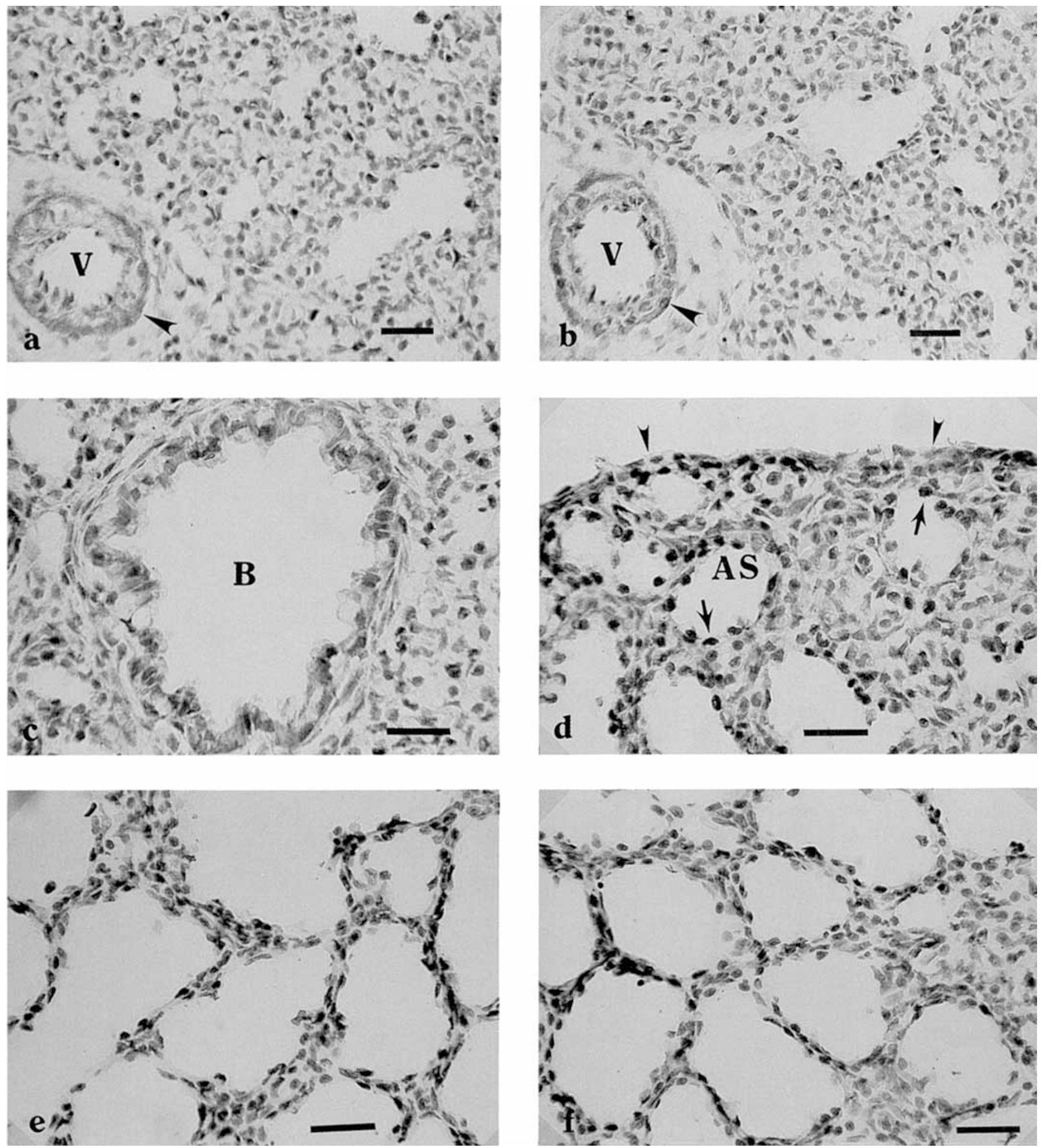

Fig. 3. Immunolocalization of PDGF-AA and PDGF-BB in late canalicular and saccular stages of fetal rat lung development. PDGF-AA, left panels $(a, c$, and $e$ ) and PDGF-BB, right panels $(b, d$, and $\mathrm{f}$ ). Bar equals $100 \mu \mathrm{m}$. $a$, Immunoreactivity to PDGF-AA in cells lining the developing air spaces, interstitial cells, and smooth muscle cells (arrowhead) of a muscular artery $(V)$ in $\mathrm{d} 20$ fetal lung. $b$, Immunoreactivity to PDGF-BB in cells lining the developing air spaces, interstitial cells, and smooth muscle cells (arrowhead) of a muscular artery $(V)$ in d 20 fetal lung. $c$, PDGFAA immunoreactivity in epithelial cells lining the bronchus $(B)$ in $\mathrm{d} 20$ fetal lung. $d$, The peripheral part of $\mathrm{d} 20$ fetal lung with positive immunoreactivity to PDGF-BB in epithelial cells (arrows) lining the developing air spaces $(A S)$ and in interstitial cells. Absence of immunoreactivity in mesothelial lining cells (arrowheads). $e$, Weak positive reactivity to PDGF-AA in a few interstitial cells of $\mathrm{d} 21 \mathrm{fetal}$ lung. $f$, Weak positive reactivity to PDGF-BB in a few interstitial cells of $\mathrm{d} 21$ fetal lung.

there is a relative increase in the proportion of epithelial cells, compared with other cell types, at this stage of fetal rat lung development. Taken together, these findings are compatible with a role for both forms of PDGF in the proliferative events occur- ring during the late canalicular stage of fetal lung development. The substantial reduction in lung PDGF-AA and PDGF-BB immunoreactivity evident on 21 and 22 of gestation suggests that PDGF are less important during the saccular stage of lung 


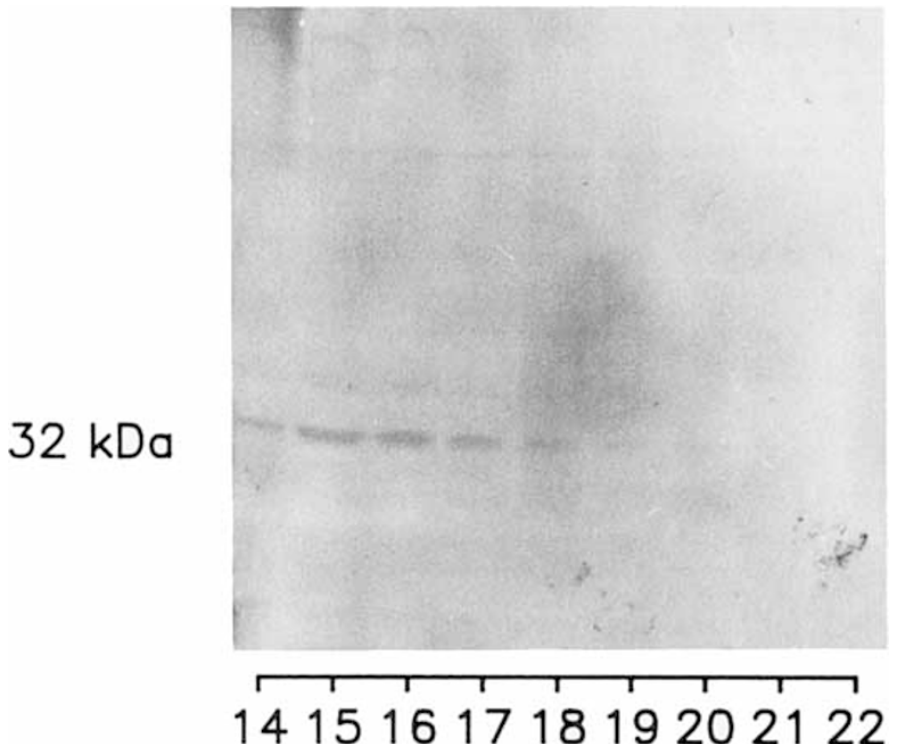

\section{GESTATIONAL AGE (days)}

Fig. 4. Western blot immunoanalysis of PDGF-AA in rat fetal lung of different gestational ages. Aliquots ( $300 \mu \mathrm{g}$ ) of protein from fetal lung homogenates were loaded on each lane and separated on $10 \%$ polyacrylamide gels under nonreduced conditions. Proteins were transferred to nitrocellulose and immunostained with PDGF-AA antibody. A single protein band of $\sim 32 \mathrm{kD}$ was detected. The PDGF-AA protein content was high in the pseudoglandular stage, after which there was a progressive reduction to term $(22 \mathrm{~d})$.

\section{$28 \mathrm{kDa}$}

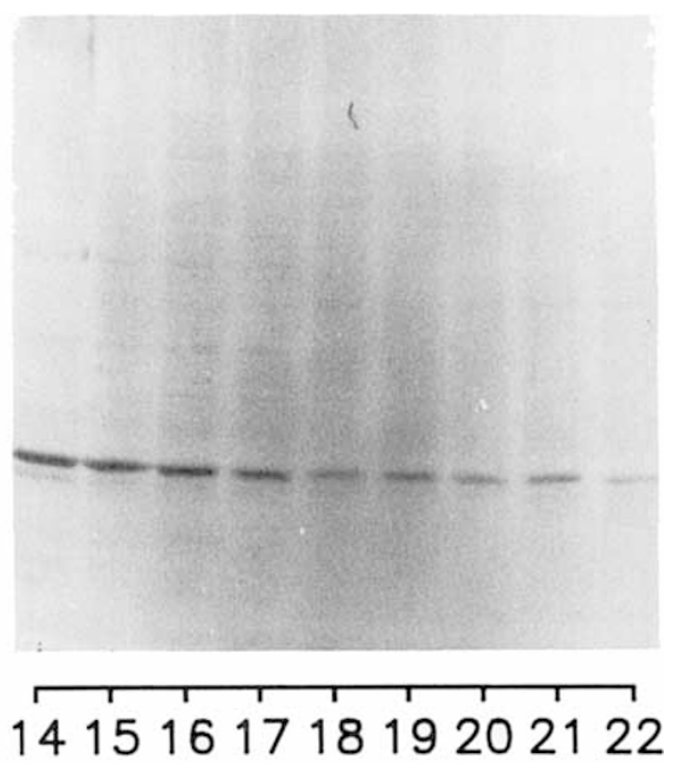

\section{GESTATIONAL AGE (days)}

Fig. 5. Western blot immunoanalysis of PDGF-BB in rat fetal lung of different gestational ages. Aliquots $(300 \mu \mathrm{g}$ ) of protein from fetal lung homogenates were loaded on each lane and separated on $10 \%$ polyacrylamide gels under nonreduced conditions. Proteins were transferred to nitrocellulose and immunostained with PDGF-BB antibody. A single protein band of $\sim 28 \mathrm{kD}$ was detected. The PDGF-BB protein content was high in the pseudoglandular stage, after which there was a progressive reduction to term $(22 \mathrm{~d})$. development, when alveolar precursors are formed. Only smooth muscle cells of the large airways and vessels had weak PDGF reactivity during the saccular stage. Relative changes in PDGF$\mathrm{AA}$ and PDGF-BB expression during the later stages of fetal lung development may occur because of regulation of PDGF peptide synthesis at the level of transcription or by altered rates of growth factor inactivation. There is a good correlation between these immunocytochemical studies and our previous observation that PDGF-A and PDGF-B mRNA levels increase markedly during the late canalicular stage of lung development but decline during the saccular stage (14). Together, these findings suggest that the observed decrease in PDGF immunoreactivity during the saccular stage of lung development is a pretranslational event.

Western blot immunoanalyses of whole lung homogenates confirmed gestation-dependent changes in protein levels of both PDGF-AA and PDGF-BB. Both PDGF-AA and PDGF-BB antibodies cross react with the PDGF-AB isoform. The observation that the antibodies detected only single proteins with apparent molecular masses of $32 \mathrm{kD}$ and $28 \mathrm{kD}$, respectively, suggests that the PDGF-AB isoform was either not present during fetal lung development or only present in undetectable amounts. The concentration of the PDGF homodimers in rat lung was greater at earlier gestations. Superficially, there is a discrepancy between our immunohistochemical findings of a marked increase in epithelial cell immunoreactivity to PDGF-AA and PDGF-BB at $20 \mathrm{~d}$ gestation and the decline in total lung PDGF-AA and PDGF-BB by Western blot immunoanalysis. However, inasmuch as lung protein content and the protein/DNA ratio increase during fetal development (25), it is possible that whole lung PDGF protein content remains constant, despite a reduced concentration relative to other lung proteins. This was confirmed when densitometric scans of the Western blots were expressed as a function of DNA content instead of protein content. The PDGF content, expressed in this way, remained relatively constant during development, and a slight increase was noted at $\mathrm{d}$ 20.

These studies demonstrate the localization of PDGF-AA and PDGF-BB to airway epithelial cells, as well as to mesenchymal cells, but do not allow us to identify the source of PDGF production, which will require in situ hybridization studies. These findings are consistent with our previous in vivo (14) and in vitro (26) observations, which suggest that fetal lung produces PDGF molecules that are involved in both epithelial and mesenchymal cell growth. Overall, these studies support a role for PDGF in airway epithelial cell proliferation during fetal lung development.

\section{REFERENCES}

1. Meyrick B, Reid LM 1977 Ultrastructure of alveolar lining and its develop ment. In: Hodson WA (ed) Development of the Lung. Marcel Dekker, New York, pp 135-214

2. Catterton WZ, Escobedo MB, Sexson WR, Gray ME, Sundell HW, Stahlman MT 1979 Effect of epidermal growth factor on lung maturation in fetal rabbits. Pediatr Res 13:104-108

3. Stahlman MT, Orth DN, Gray ME 1989 Immunocytochemical localization of epidermal growth factor in the developing human respiratory system and in acute and chronic lung disease in the neonate. Lab Invest 60:539-547

4. Beck F, Samani NJ, Penschow JD, Thorley B, Tregear GW, Coghlan JP 1987 Histochemical localization of IGF-I and -II mRNA in the developing rat embryo. Development 101:175-184

5. Han VKM, Hill DJ, Strain A, Towle AC, Lauder JM, Underwood LE, D'Ercole AJ 1987 Identification of somatomedin/insulin-like growth factor immunoreactive cells in the human fetus. Pediatr Res 22:245-249

6. Heine UI, Munoz EF, Flanders KC, Roberts AB, Sporn MB 1990 Colocaliza tion of TGF-beta 1 and collagen 1 and III, fibronectin and glycosaminoglycans during lung branching morphogenesis. Development 109:29-36

7. Ross R 1989 Platelet-derived growth factor. Lancet 1:1179-1182

8. Heldin CH, Westermark B 1990 Platelet-derived growth factor: mechanism of action and possible in vivo function. Cell Regulation 1:555-566

9. Östman A, Rall L, Hanmacher A, Wormstead MA, Ciot D, Valenzuela P, Betsholtz C, Westermark B, Heldin CH 1988 Synthesis and assembly of a functionally active recombinant PDGF-AB heterodimer. J Biol Chem 263:16202-16208

10. Robbins KC, Leal F, Pierce JH, Aaronson SA 1985 The v-sis/PDGF-2 trans- 
forming gene product localizes to cell membranes but is not a secretory product. EMBO J 4:1783-1795

11. Antoniades HN, Galanopoulos T, Neville-Golden J, Kiritsy CP, Lynch SE 1991 Injury induces in vivo expression of platelet-derived growth factor (PDGF) and PDGF receptor mRNAs in skin epithelial cells and PDGF mRNA in connective tissue fibroblasts. Proc Natl Acad Sci USA 88:565569

12. Lee K, Bowen-Pope DF, Reed RR 1990 Isolation and characterization of the $\alpha$ platelet-derived growth factor receptor from rat olfactory epithelium. Mol Cell Biol 10:2273-2246

13. Deuel TF 1987 Polypeptide growth factors: role in normal and abnormal cell growth. Annu Rev Cell Biol 3:443-492

14. Buch S, Jones C, Sweezey N, Tanswell K, Post M 1991 The developmental expression of platelet-derived growth factor and growth related genes in rat fetal lung. Am J Respir Cell Mol Biol 5:371-376

15. Tanswell AK, Han RNN, Jassal D, Post M 1991 The response of small vessel endothelial cells from fetal rat lung to growth factors. J Dev Physiol 15:199209

16. Caniggia I, Tseu I, Han RNN, Smith BT, Tanswell K, Post M 1991 Spatial and temporal differences in fibroblast behaviour in fetal rat lung. Am J Physiol 261:L424-L433

17. Simmons DM, Arriza JL, Swanson LW 1989 A complete protocol for in situ hybridization of $m$ RNAs in brain and other tissue with radio-labelled singlestranded RNA probes. J Histotechnol 12:169-181

18. Hsu SM, Raine L, Fanger H 1981 Use of avidin-biotin-peroxidase complex
$(A B C)$ in immunoperoxidase technique: a comparison between $A B C$ and unlabelled antibody (PAP) procedures. J Histochem Cytochem 29:577-580 19. Bradford MM $1976 \mathrm{~A}$ rapid and sensitive method for the quantitation of microgram quantities of protein utilizing the principle of protein dyebinding. Anal Biochem 72:248-254

20. Laemmli UK 1970 Cleavage of structural proteins during assembly of bacteriophage. Nature 277:680-685

21. Towbin H, Staehelin T, Gordon J 1979 Electrophoretic transfer of protein from polyacrylamide gels to nitrocellulose sheets: procedure and some applications. Proc Natl Acad Sci USA 76:4350-4354

22. Sasahara M, Fries JWU, Raines EW, Gown AM, Westrum LE, Frosch MP, Bonthron DT, Ross R, Collins T 1991 PDGF B-chain in neurons of the central nervous system, posterior pituitary, and in a transgenic model. Cell 64:217-227

23. Hsiu JY, Ruit KG, Ya XW, Parks WC, Snider WD, Deuel TF 1991 PDGF Achain gene is expressed by mammalian neurons during development and in maturity. Cell 64:209-216

24. Adamson IYR, King GM 1984 Sex differences in development of fetal rat lung. I. Autoradiographic and biochemical studies. Lab Invest 50:456-460

25. Tanswell AK, Freeman BA 1984 Pulmonary antioxidant enzyme maturation in the fetal and neonatal rat. I. Developmental profiles. Pediatr Res 18:584587

26. Stiles AD, Smith BT, Post M 1986 Reciprocal autocrine and paracrine regulation of growth of mesenchymal and alveolar epithelial cells from fetal lung. Exp Lung Res 11:165-177 